\title{
¿La poética de la verdad o la verdad sobre una poética?: Segunda mesa redonda sobre Arguedas
}

\author{
Miguel Ángel Huamán VillaVicencio \\ Universidad Nacional Mayor de San Marcos \\ miguelangel_huaman@yahoo.com
}



Hace algunos años, un colega extranjero, que estuvo de visita por nuestras universidades, me comentaba que le llamaba la atención la cantidad de eventos que se organizaban todas las semanas. Asimismo, estaba sorprendido de que siempre tuvieran oyentes o asistentes. Tomé en cuenta de que para un observador externo, el ambiente académico, educativo, cultural del país aparecía predominantemente dominado por certámenes marcadamente dialógicos.

Efectivamente, en las casi ciento veinte universidades que hay en el Perú, podemos afirmar sin temor a equivocarnos que todos los días se convoca por lo menos a un coloquio, conversatorio, mesa redonda, encuentro, conferencia y una diversidad de otros eventos, cuyo formato elegido parece priorizar el promover el intercambio de ideas, opiniones, juicios entre los expositores y el público asistente. Lo paradójico del caso es que en todas estas actividades orientadas al intercambio de ideas y al debate, lo que menos se produce es precisamente el diálogo. En realidad, el evento sirve para que los expositores lean o hablen, cada quien a su turno, sin que se produzca discusión ni preguntas del público ni que exista un verdadero interés en generar debates, solo en cumplir con el programa estipulado.

He constatado esta peculiaridad, en casi todo el territorio nacional, a donde he sido invitado y cuando me ha correspondido participar en dichas actividades, y en todos esos certámenes, gracias a mi insistencia, se ha dado ocasión a pocas preguntas de los espectadores o réplicas y aclaraciones esporádicas con los integrantes de la mesa. Sin duda resulta un rasgo distintivo de nuestra vida cultural que en el terreno intelectual aún estemos en una "tradición oral" y no debe sorprendernos que esta sea predominantemente monológica, autoritaria, egocéntrica, hecha exclusivamente para que la autoridad intelectual, las grandes luminarias del conocimiento muestren su saber, cada quien a su turno. 
Obviamente no se trata de una oralidad primaria, sin contacto con la escritura, propia de etnias cuya memoria colectiva se transmite por vía de mitos o relatos tradicionales, sino de un fenómeno propio de la oralidad globalizada de los medios audiovisuales, de lo informático y de la cultura del espectáculo, en su variante más ilustrada. El público que asiste a cuanta charla o conferencia de su interés encuentra, difundida a través de volantes, radio, prensa escrita y televisiva, mensajes de textos o internet, está conformado en forma heterogénea por estudiante de diversos niveles, empleados o trabajadores de las más distintas empresas, profesionales jóvenes o jubilados, todos ellos con una característica en común: enterados por diversos medios de la actividad, gratuita o pagada, asisten más que para informarse para formarse.

Es decir, no tienen tiempo, recursos, ganas o costumbre de investigar, con la carga de lectura y estudio que implica, pero valoran lo que escuchan como fuente de un saber verdadero, que obtienen sin esfuerzo, cuyos conocimientos repetirán en su entorno laboral o social, y del que obtendrán, de ser posible, hasta una constancia de asistencia, mejor si es un certificado. Esta práctica, tal vez consecuencia del desborde popular andino, pareciera sustentarse en una continuidad entre la oralidad primaria, tradicional de las comunidades, y la terciaria, de la aldea global, que la actual cultura del espectáculo, con su soporte massmediático, ha impuesto. Lo cierto es que la gente cada vez lee menos libros, pero recibe a través de la voz e imagen de un intermediario (locutor, periodista, expositor, conferencista, etc.) más información que constituye su bagaje principal de conocimientos. En el Perú hay muchos intelectuales y profesionales de "oídas" y de currículum vitae, que no lee ni investigan ni escriben desde su graduación.

Esta larga introducción, con la anuencia de los lectores, me permite hacer una precisión que sirve de contexto para el libro que reseñamos: no todos los eventos de esa "tradición oral" son intrascendentes o epidérmicos, algunos constituyen verdaderos documentos históricos e hitos para la comprensión de nuestros procesos culturales o literarios. Uno de ellos, precisamente, fue el primer conversatorio sobre la novela Todas las sangres que organizó el Instituto de Estudios Peruanos en 1965, motivo por el cual, fue editado años después y reimpreso este año. La importancia de esa publicación ha sido reconocida por los estudiosos, pero no por las razones que uno podría imaginarse: porque fue ejemplo de un diálogo fructífero entre los asistentes, conferencistas y espectadores, sino porque fue un tremendo fracaso.

Se invitó a un reconocido escritor de esos años, José María Arguedas, autor de una reciente novela de gran repercusión en el momento, Todas las sangres; a un grupo de literatos, encabezado por Alberto Escobar, a quien consideramos en el ambiente académico como el fundador de los estudios literarios moder- 
nos, basados en el análisis y la comprensión de los textos y no en impresiones subjetivas sobre la vida o la biografía de los escritores; y a un grupo de destacados científicos sociales.

La intención era propiciar un diálogo, de ahí el nombre de Mesa Redonda, entre especialistas de la literatura y de las ciencias sociales. El conversatorio terminó convertido en un enjuiciamiento al escritor, que fue acusado del delito de que sus novelas no reflejaban la realidad social y cultural del país. Solo uno de los participantes, Alberto Escobar, lo defendió, pero su voz fue avasallada por los demás. El resultado, se sintetiza en la frase pregunta de Arguedas: “¿He vivido en vano?".

Cuarenta y seis años después, el Congreso de la República, el Ministerio de Cultura y el Ministerio de Educación, organizaron en la Biblioteca Nacional del Perú un segundo coloquio ${ }^{1}$ para "darles a los académicos amigos de Arguedas, la posibilidad histórica de ratificar o modificar sus pareceres ensayando visiones alternas a lo discutido en el IEP”. Es decir, se convoca a un certamen desde las instancias más representativas de la actividad cultural del país, con un espíritu de reparación con el ilustre escritor, con voluntad de diálogo y con afán de rendir homenaje a su figura en el centenario de su nacimiento.

Días antes de que concluya el año jubilar, el libro que recoge las intervenciones de esta segunda mesa redonda, aparece editado en formato tabloide, poco usual para una publicación académica y literaria, pero más apto para el despilfarro de fotografías que rinde tributo al henchido ego de los convocados al conversatorio. En las palabras del Director de la Biblioteca Nacional del Perú que sirven de presentación al texto se afirma que "al repetirse el mismo acto con algunos de los mismos protagonistas, como en un ritual mágico o de exorcismo, la figura de Arguedas quedó liberada para siempre del demonio ideológico de sus captores". ¿Cómo se produjo este extraordinario acto de reconciliación histórica y de enmienda del grave pecado cometido contra un escritor, cuyo centenario de su nacimiento se ha venido celebrando con múltiples actos artísticos, certámenes académicos y publicaciones diversas en el país?

La posible respuesta la empezamos a encontrar si prestamos atención al título elegido para la publicación: Arguedas. Poética de la verdad, cuyo sentido se explicita en el propio texto donde se afirma que "no escribió cuentos o novelas de ficción, sino testimonios verdaderos del alma", pues "sus novelas sociales, después de todo, pretendían ser un fiel reflejo de la realidad; una poética de la verdad social y cultural que él conocía". Tan contundente declaración parecería significar una aceptación del error cometido, pero este otorgamiento no implica un acto de enmienda de las propias posiciones esgrimidas sino, en pa-

1 Ver la edición de esta segunda mesa redonda: Arguedas. Poética de la verdad. Segunda mesa redonda sobre Todas las sangres. Lima, Biblioteca Nacional del Perú, Fondo Editorial, 2011; 97 pp. 
labras de Matos Mar, uno de los participantes de la primera mesa redonda, que "Arguedas narraba la realidad del proceso peruano correspondiente a 1940, mientras que sociólogos y antropólogos habíamos avanzado desde 1946".

¿Cuál fue la postura del otro de los asistentes a la mesa redonda del 65, que también estaba en esta oportunidad? El destacado científico social, al que hacemos referencia, coincidente con lo reseñado, ya no sacó en cara al personaje indígena protagonista de la novela arguediana el no expresar sus teorías sobre los procesos de mestizaje modernizador, sino que puso la vida y obra de Arguedas como portadoras de la paradoja de la colonialidad del poder que ahora propugna. Es decir, los dos conspicuos sociólogos, como en 1965, reiteraron el error de juzgar lo literario desde ópticas que dejan de lado su naturaleza estética, sin comprender que para poder dialogar era necesario que hablaran no como especialistas en ciencias sociales, sino como simples lectores capaces de disfrutar del placer del texto, al decir de Barthes, y de ampliar sus percepción de los procesos que estudiaban, con la sensibilidad y la emoción artística.

¿A quiénes más convocaron para esta segunda mesa redonda y cuáles fueron las reflexiones que realizaron, cuya versión escrita recoge el libro? La tertulia se amplió con la inclusión de amigos personales del escritor fallecido, un reconocido artista plástico y connotados científicos sociales, de amplio prestigio académico. La frase con la que abre su intervención uno de ellos, que fue precisamente el editor de la primera mesa redonda, resume la naturaleza de las intervenciones de los expositores de esta segunda mesa: "Mi intervención es sobre el Arguedas observador, el apasionado estudiosos del mundo andino, el etnólogo, para lo cual prescindo del Arguedas literato".

¿Estuvo presente algún crítico literario para cumplir el papel de defensor del novelista? No. Ninguno de los herederos de Alberto Escobar fue invitado y, por ello, en esta ocasión, nadie presentó el estado actual de las interpretaciones de la obra de Arguedas en los estudios literarios, que se han desarrollado muchísimo, cuyas propuestas no se han quedado ancladas en 1965. La crítica literaria arguediana vigente no se centra en Todas las sangres ni en el eje modernidad-tradición ni afinca en el indigenismo su producción discursiva. Mucho menos asume lo que se ha denominado una antropologización del discurso sobre los Andes, pues rechaza la triple A: la identidad entre Andes = Antropología = Arguedas. La escritura, lo ético y la afectividad son algunos de los ejes que las recientes investigaciones literarias indagan, labor de explicación textual del sistema de significación del discurso arguediano que ha ubicado al autor andahuaylino como hito en la reflexión sobre la sociedad, la cultura y la identidad en los Andes y Latinoamérica.

Es lamentable que ninguna de estas contribuciones haya podido ser escuchada y difundida entre el público participante, por un afán de figuración, una 
política de promoción cultural oportunista y una actitud concesiva frente al poder de la ideología consumista dominante, que promueve sólo aquello que contribuya al espectáculo, mas no a la conciencia crítica ni al diálogo y la tolerancia. Asimismo, deviene ridículo que los funcionarios, representantes y responsables de las entidades estatales y públicas que promueven la educación, la cultura y la equidad social discriminen, o como dicen los mexicanos "ninguneen", a los intelectuales, académicos e investigadores de las universidades nacionales y públicas, cuya opinión crítica y juicio alternativo permitiría una visión más plural sobre los temas propios de nuestra realidad cultural y literaria.

En resumen, consideramos que el libro Arguedas Poética de la verdad. Segunda mesa redonda sobre todas las sangres (Lima, Biblioteca Nacional del Perú, 2011), constituye paradójicamente un valioso documento histórico porque permite apreciar que en los procesos socio-culturales algunos acontecimientos adquieren su condición de traumáticos porque se repiten, lo que nos facilita apreciar sintomáticamente la tensión que determina nuestra representación simbólica y la perentoriedad de una conciencia crítica, que propicie un cambio en el camino a instaurar una tradición de diálogo, tolerancia y solidaridad en nuestra cultura, condición indispensable para un desarrollo sostenible con inclusión social.

La conclusión de esta valiosa iniciativa de convocar una segunda mesa redonda y publicar sus intervenciones, no estoy seguro que sería como ha aseverado uno de los participantes que Arguedas estaría bailando y cantando, sino tal vez preguntándose: ¿he muerto en vano? En tal caso, habría que recordarle sus propias palabras: “ ¿Es que no vale nada la vida? No contestes que no vale. Más grande que mi fuerza en miles de años aprendida; de los músculos de mi cuello en miles de meses, miles de años fortalecidos es la vida, la eterna vida mía, el mundo que no descansa, que crea sin fatiga; que pare y forma como el tiempo, sin fin y sin precipicio."

En medio de tanto evento celebratorio del nacimiento de José María, de tanta tradición oral, de tanto monólogo y tan poco diálogo, y del intento de contraponer su figura a la de Mario Vargas Llosa, nuestro premio Nobel de Literatura, me viene a la memoria las agudas palabras de Voltaire: "Cuando un pueblo ya no lee a sus escritores, los celebra, les rinde homenaje". En tal sentido, debemos reiterar que la mejor manera de reivindicar a un escritor es leyendo su obra.

Para finalizar, me gustaría decir lo siguiente: desde nuestro punto de vista dos acontecimientos iluminan el escenario cultural del año que abre la segunda década del tercer milenio en el Perú. La obtención del Premio Nobel de Literatura por Mario Vargas Llosa y la conmemoración de los cien años del nacimiento de José María Arguedas. Ambos escritores simbolizan los problemas y las 
posibilidades del Perú como nacionalidad en formación. Una de las intenciones de nuestras palabras en el acto de presentación del texto reseñado, al que fui invitado, y que reitero en este escrito ha sido exhortar a las instituciones, a los académicos e intelectuales para que promuevan la lectura de las obras de estos dos grandes literatos en el colegio. En tal sentido, debería reincorporarse la asignatura de literatura en las escuelas, como una competencia propia, que propicia en los niños y jóvenes el diálogo y el respeto por la ideas de los otros, porque esas es la virtud del discurso estético-literario. Sólo así lograremos construir una tradición de diálogo, fortalecer una cultura del respeto y la solidaridad, y desarrollar una reflexión colectiva que incorpore ambos geniales imaginarios en un sentido integrador, a favor de una identidad nacional. 